\title{
ANÁLISIS MULTIESCALAR DEL PAISAJE SEMIÁRIDO DE LA REGIÓN DE MURCIA Y PROPUESTA DE GESTIÓN
}

\author{
María Degania Medina Vidal \\ Universidad Politécnica de Cartagena
}

\section{RESUMEN}

El presente artículo expone la metodología y los resultados del análisis realizado sobre el paisaje semiárido de la Región de Murcia, planteando su uso como recurso para generar alternativas a la ordenación del territorio y usos del suelo rural tradicionales, que permitan nuevos modelos de desarrollo sostenibles. Se trabaja en diferentes escalas, concretando en la potencialidad y oportunidad que ofrece el paisaje del litoral, y realizando una propuesta de uso y gestión de una finca rural de la Sierra de la Almenara (Águilas).

Palabras clave: gestión del paisaje; Sierra de la Almenara; desarrollo rural, ordenación territorial

\section{MULTISCALAR ANALYSIS OF THE SEMI-ARID LANDSCAPE IN REGIÓN DE MURCIA (SPAIN) AND MANAGEMENT PROPOSAL}

\section{ABSTRACT}

The present work describes the methodology and results derived from the analysis of the semi-arid landscape in Región de Murcia (southeast Spain), as a resource to propose alternative land planning strategies and rural territory uses, allowing new sustainable development models to emerge. Different scales are used, specifying the potencial and opportunities offered by the litoral are a landscape, and experimenting new uses and management options in a rural estate located in Sierra de la Almenara (Águilas).

Keywords: landscape management; Sierra de la Almenara; rural development; land planning

\footnotetext{
${ }^{1}$ Este artículo es un resumen de la investigación y propuesta experimental llevadas a cabo en el Proyecto Final Específico del Grado en Arquitectura de la Universidad Politécnica de Cartagena titulado Bienvenidos a Chuecos. Parque Ecotemático del Levante Semiárido. Tutores: Marcos Ros Sempere, Fernando Miguel García Martín ${ }^{1}$ El desmesurado consumo de suelo entre 1990 y 2000 según las fotografías satélite del proyecto CorineLandCover supone un aumento del 52,5\% de zonas urbanizadas en el litoral de Murcia. (HILDENBRANDT SCHEID, 2003). E-mail: mariadeganiamedina @ gmail.com
} 


\section{INTRODUCCIÓN}

\subsection{ANTECEDENTES Y SITUACIÓN ACTUAL}

Los modelos de ordenación del territorio en el sureste español, y especialmente en el litoral de la Comunidad Autónoma de Murcia, caracterizado por la existencia de espacios naturales de alta calidad y fragilidad ecológica y paisajística, han seguido criterios contrarios a la preservación de los mismos. Los procesos que han alterado estos espacios litorales en mayor medida han sido la minería (desde finales del siglo XIX), la promoción residencial y grandes desarrollos urbanísticos que comenzaron en los años 60 (IBARRA MARINAS et al., 2017); y el incremento de la agricultura intensiva y las superficies de invernadero gracias al trasvase TajoSegura en la década de los 80 . Siguiendo esta dinámica durante las últimas décadas, el consumo del territorio del litoral se ha basado en el concepto del "resort" y el campo de golf, el turismo residencial como aprovechamiento básico. (ANDRÉS SARASA, 1995, 2004).

En este contexto socioeconómico de expansión inmobiliaria, el gobierno regional se sumó a la tendencia desarrollista en 2004 con un instrumento de planificación, las Directrices y Plan de Ordenación del Litoral de la Región de Murcia, (incluyendo la Actuación de Interés Regional Marina de Cope $^{2}$ ), diseñadas según varios autores (VERA REBOLLO et al., 2006, ESPEJO MARÍN, 2008, PÉREZ MORALES et al., 2015) a medida para estructurar y organizar el ritmo frenético de construcción de viviendas para turismo residencial y seguir dando la espalda a los valores ambientales de la zona.

Posteriormente, este modelo se vio frenado a partir de 2007 a causa de la última crisis económica. A partir de ese momento el panorama social e institucional ha evolucionado hacia nuevas opciones, especialmente en cuanto al desarrollo de zonas rurales, la gestión sostenible de espacios naturales, la apreciación y estudio del paisaje, y la inclusión de este en la planificación turística (CEBRIÁN ABELLÁN, 2008).

Estas nuevas opciones han sido desarrolladas por diversos autores, incidiendo en la relación entre turismo y paisaje para el desarrollo rural (ROMERO DÍAZ, 2002, LÓPEZ CUQUEJO, 2002, ANDRÉS SARASA, 2014, SANTOS PAVÓN et al., 2016). Sin embargo, la utilización del paisaje como una herramienta más de ordenación del territorio y aprovechamiento turístico no ha tenido grandes experiencias en la práctica en el territorio de la Región, más allá de la elaboración de una Estrategia de paisaje (incluyendo Observatorio y Atlas de paisaje) por parte de la Comunidad Autónoma ${ }^{3}$.

El paisaje semiárido de la Región de Murcia es el producto y el testimonio de multitud de factores, siendo el clima-y la consecuente escasez de agua-el más influyente de todos. Este ha determinado la existencia de ecosistemas concretos que conforman espacios naturalescuyo valor, diversidad y calidad ecológica es indiscutible y ha sido ampliamente estudiado científicamente (LÓPEZ BERMÚDEZ et al., 2003, y CONESA GARCÍA, 2006).

\subsection{ESPACIO EXPERIMENTAL: PARAJE DE CHUECOS}

El paraje de Chuecos, en la Sierra de la Almenara (término municipal de Águilas) ${ }^{4}$ es una finca de aproximadamente $480 \mathrm{Ha}$ en la que se han desarrollado experiencias de agricultura ecológica y convenios educativos y de investigación con la Universidad de Murcia hasta la fecha. La finca se sitúa en el interior del área ZEPA ES0000261 de las Sierras Almenara, Moreras y Cabo Cope, y del LIC ES6200035 de la Sierra de la Almenara.

\footnotetext{
${ }^{2}$ Actuación anulada por sentencia 428/2013 del TSJ de Murcia, de 31 de Mayo de 2013

${ }^{3}$ El documento marco Estrategia del paisaje de la Región de Murcia, desarrollado por la Administración Regional, recoge el siguiente objetivo: "Reconocimiento de la potencialidad del Paisaje como recurso económico" (Estrategia del paisaje de la Región de Murcia, 2011)

${ }^{4}$ Iniciativa dirigida por el ingeniero industrial Domingo Jiménez Beltrán, ex director de la Agencia Europea de Medio Ambiente. En verano de 2003, junto a otros socios, constituye la sociedad "Castillo de Chuecos S.L." que consigue mediante compra la propiedad de la finca denominada "Castillo de Chuecos".
} 
Toda esta reflexión previa, unida a la existencia de este lugar como sujeto experimental para el desarrollo de la investigación, llevó a proponer un tema como este como Proyecto Final Específico del Grado en Arquitectura de la Universidad Politécnica de Cartagena, titulado Bienvenidos a Chuecos: Parque Ecotemático del Levante semiárido.

\subsection{OBJETIVOS}

- Exponer la metodología y los resultados del análisis e investigación realizados sobre el paisaje semiárido de la Región de Murcia a diferentes escalas, insistiendo en los altos valores de calidad paisajística derivados de estos análisis.

- Describir los procesos y la metodología de generación de la propuesta experimental de actuación en el paraje de Chuecos.Se identifican las unidades y las relaciones que lo componen, a fin de elaborar criterios de intervención acordes con la lógica intrínseca del lugar, que puedan aplicarse en otros territorios de características similares, y puedan servir como referencia en materia de ordenación territorial.

- Desarrollar el concepto de la utilización del paisaje como recurso para modelos alternativos de desarrollo rural, ejemplificándolo de forma teórica y experimental en la mencionada finca mediante una propuesta de gestión basada en la unión de distintas actividades: agricultura ecológica y respetuosa con las características del entorno, investigación, educación y ecoturismo sostenible. Se expone resumidamente el plan de actuación (objeto principal del mencionado PFG), que comprende un programa, ordenación, uso y gestión, económica y arquitectónicamente sostenible.

\subsection{METODOLOGÍA Y ESTRUCTURA}

\subsubsection{Fase 1: análisis multiescalar}

Se utilizan dos métodos de trabajo paralelos (Figura 1): un trabajo de campo basado en profundizar en el conocimiento del territorio junto con la generación de información propia (fotografías, croquis, etc.); y un estudio y procesado de toda la información disponible referente a la zona. Estos métodos de trabajo se utilizan en la fasede investigación denominada "análisis multiescalar", empezando por contextualizar el litoral de la Región de Murcia dentro de la franja semiárida del levante español y concluyendo en el paraje de Chuecos.

La primera escala de análisis abarca toda la provincia biogeográfica Murciano-Almeriense. En ella se estudian los siguientes rasgos de los espacios naturales de la provincia: nivel de protección; y dotación de infraestructuras y equipamientos relacionados con la conservación, educación e investigación ambiental, y ecoturismo.

A continuación se acota el área de análisis al litoral de la Región de Murcia, estudiando la clasificación del suelo, el modelo de desarrollo territorial, la dinámica poblacional y los datos existentes sobre paisaje elaborados por la Comunidad Autónoma junto a análisis propios.

Posteriormente se estudia el área de la Sierra de la Almenara, ubicando el valle de Chuecos en la misma, las conexiones del lugar con el resto de la sierra, los tiempos de desplazamiento en coche, los hitos y lugares de interés turístico, y los núcleos de población y dotación de equipamientos.

Por último, se realiza el análisis del paraje de Chuecos como base para la siguiente fase de trabajo, estudiando el medio físico y biológico (morfología del valle, altitud, pendientes, redde caminos y accesos, hábitats, climatología, insolación, pendientes y orientaciones; geología, riesgos; especies vulnerables y singulares) y el paisaje. Este se realiza siguiendo una metodología adaptada mediante un método mixto que incorpora la subjetividad aceptada a valores objetivos (AGUILÓ ALONSO, 2004). Se genera una división en unidades paisajísticas ("UP") para llevar a cabo el análisis y la valoración (ESCRIBANO et al., 1991). Esta división se basa en criterios perceptivos (semejanza visual, cambio de cuenca visual), y físicos (topografía, pendientes, orientaciones, geología, hidrología, hábitats, etc.). La metodología que 
se propone para la valoración visual de las unidades se basa en tres parámetros (calidad, absorción, exposición) que dan lugar a un cuarto (fragilidad), según un método inspirado en Escribano et al., 1991.

\subsubsection{Fase 2: generación de la propuesta}

Concluida la etapa de investigación se inicia la segunda fase, "generación de la propuesta" (Figura 1), en la que se desarrollan las herramientas utilizadas para la creación del proyecto, basadas en descomponer la estructura del lugar en sus unidades más básicas. Estas unidades mínimas se sitúan en diferentes capas de observación para facilitar el entendimiento del lugar, como piezas que se relacionan de determinada manera generando estructuras mayores, y finalmente formando un organismo global. Se identifican así las relaciones existentes entre las partes, y entre estas y el conjunto.

\subsubsection{Fase 3: Proyecto experimental de intervención}

La tercera fase consiste en exponer resumidamente el Plan de Actuación (Figura 1) del Proyecto experimental de intervención en la finca en el que se establecen los criterios de ordenación, uso y gestión del lugar. Estas actuaciones se han desarrollado en profundidad en el ya mencionado Proyecto Final de Grado.

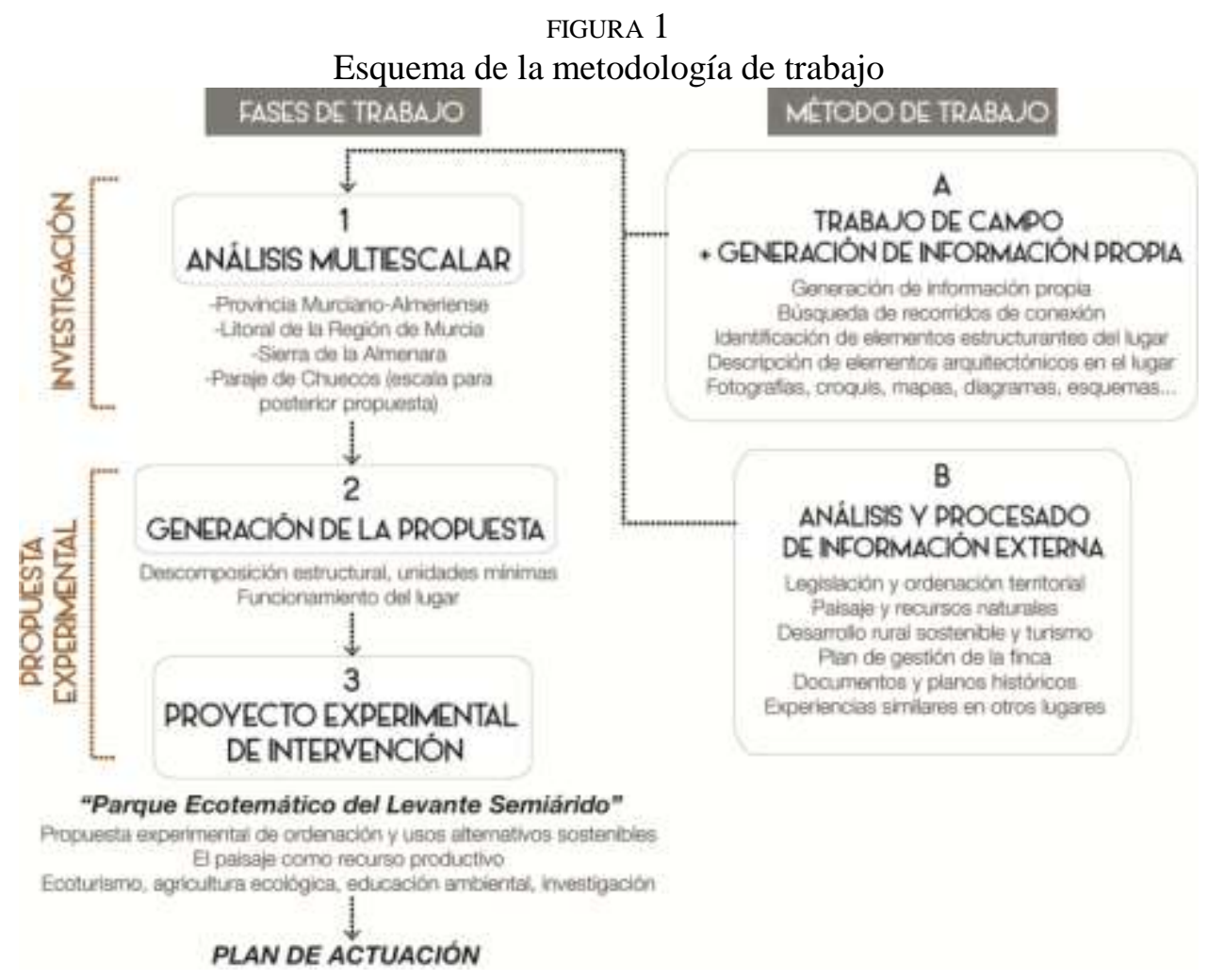

Fuente: Elaboración propia

\section{RESULTADOS Y DISCUSIÓN. FASE ANÁLISIS MULTIESCALAR}

\subsection{PROVINCIA BIOGEOGRÁFICA MURCIANO-ALMERIENSE}

Tras la observación de los datos referentes a nivel de protección y grado de dotación de equipamientos de los espacios naturales, se obtiene el parámetro "grado de protección y puesta en valor", mediado entre los dos anteriores (Figura 2). De esta forma se observa la existencia de dos polos de alto grado, en el polo oeste con Cabo de Gata como máximo representante, y el 
polo este con El Valle y Carrascoy. El siguiente espacio natural con más alto grado es Calblanque, al sureste. Sin embargo, el espacio entre estos tres polos, pese a tener una gran superficie de espacios naturales de calidad y con un nivel considerable de protección,está totalmente falto de equipamientos, lo que disminuye su grado de puesta en valor. Por ejemplo, se puede observar cómo Sierra Cabrera y Sierra Almagrera, Pinar y Aguilón carecen de protección a nivel autonómico y de equipamientos, por lo que aparecen clasificados en este esquema con un grado de protección y puesta en valor "inexistente" (Figura 2).

Queda resaltada la existencia de dos concentraciones de espacios naturales con un alto nivel de protección y dotación en cada uno de los extremos de la franja, mientras que la zona central, equivalente al área comprendida entre S. Almagrera y C. Tiñoso, aparece con un nivel mucho menor. El paraje de Chuecos, objeto de la propuesta de gestión paisajística, se encuentra en esta área, por lo que podría contribuir a la puesta en valor, conservación, concienciación, educación e información sobre estos espacios naturales que han quedado en un segundo plano por detrás de los grandes protagonistas (Cabo de Gata y El Valle y Carrascoy) pese a tener características paisajísticas, ambientales y ecológicas muy similares.

\section{FIGURA 2}

Determinación del grado de protección y puesta en valor
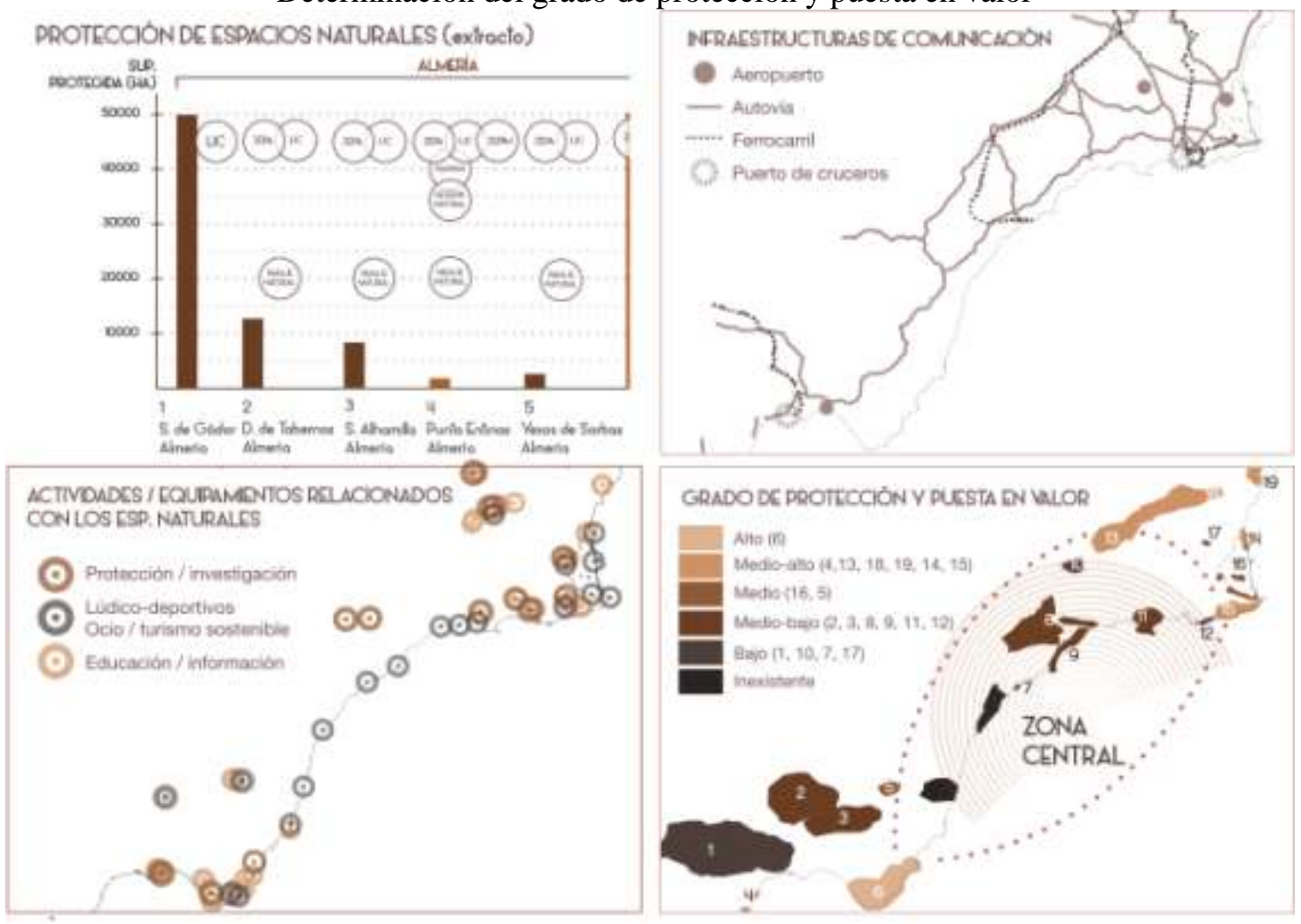

Fuente: Elaboración propia a partir de la cartografía del Instituto Geográfico Nacional y la información extraída de la Consejería de Medio Ambiente y Ordenación del Territorio (Junta de Andalucía) y la Dirección General de Medio Ambiente (Región de Murcia)

\subsection{LITORAL DE LA REGIÓN DE MURCIA}

Se observa que la mayor parte de los espacios naturales del litoral aparecen evaluados como de alta calidad paisajística, y de muy alta en el caso de las sierras de Cartagena ${ }^{5}$ (Figura 3). Sin embargo, la existencia de equipamientos relacionados con la conservación de los mismos, su puesta en valor y difusión de valores de respeto y educación ambiental y paisajística es mínima.

\footnotetext{
${ }^{5}$ Según los estudios de paisaje realizados por la Comunidad Autónoma de la Región de Murcia.
} 
Frente a estos datos, se observa el mapeado de los "puntos calientes" en los que se han realizado grandes operaciones urbanísticas (Figura 3).

En cuanto a la dinámica poblacional, la mayoría de la población de estos municipios reside en núcleos urbanos, mientras que un reducido porcentaje habita en las zonas rurales, donde pocos núcleos de población apenas llegan a los 1000 habitantes, encontrando muchas poblaciones en la Sierra de la Almenara en las que se encuentran por debajo de los 100 habitantes. Además, las ciudades costeras sufren un drástico crecimiento de su población en verano (Figura 4).

Frente a esta realidad, en el modelo de ordenación del territorio a nivel de legislación autonómica (Directrices y Plan de Ordenación del Litoral de la Región de Murcia) se observa la gran cantidad de suelo que se clasifica como urbanizable, incluyendo toda la Marina de Cope ${ }^{6}$ (espacio natural protegido) (Figura 4).

FIGURA 3

Catalogación de los paisajes por parte de las administraciones frente a actividades desarrolladas

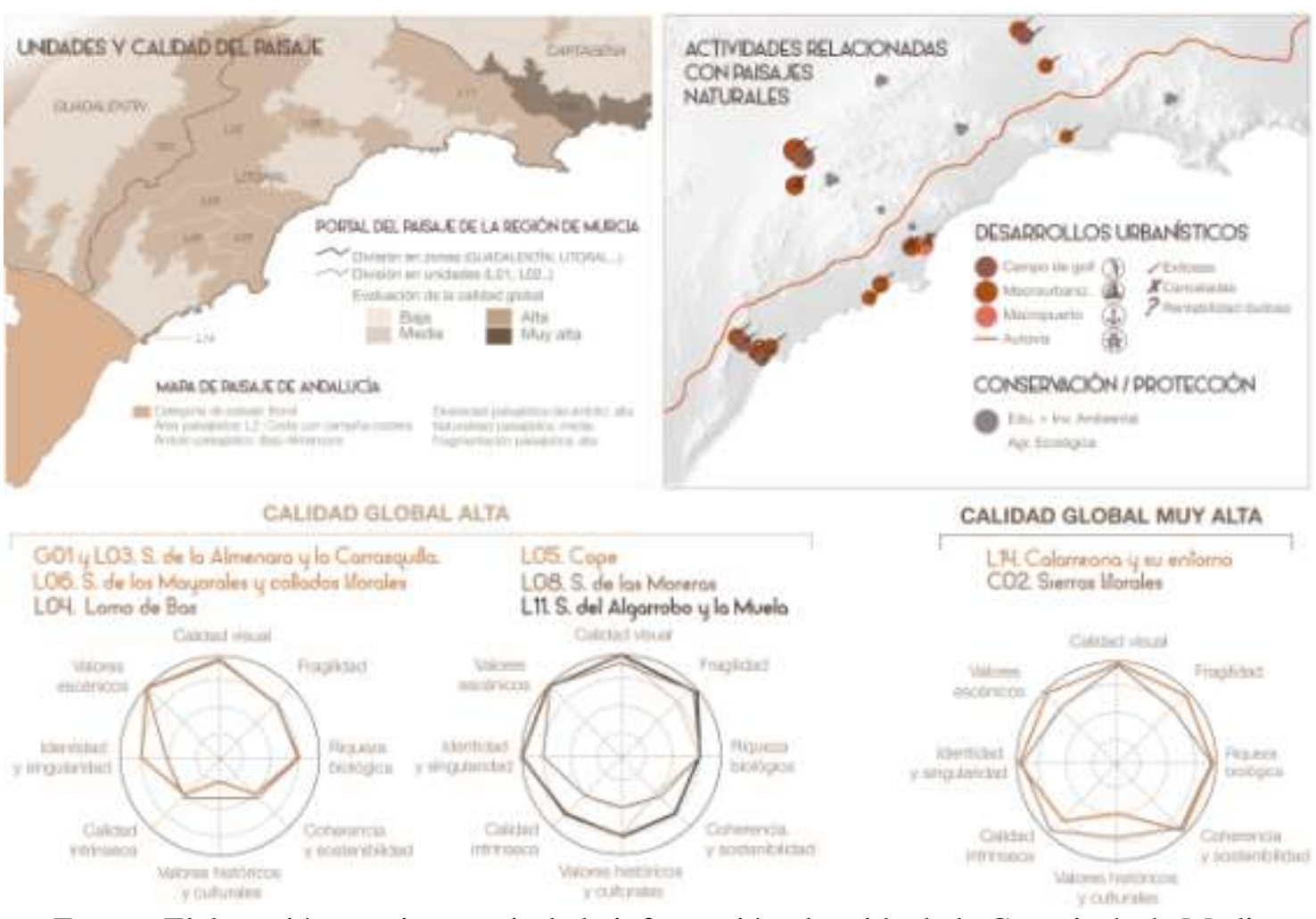

Fuente: Elaboración propia a partir de la información obtenida de la Consejería de Medio Ambiente y Ordenación del Territorio (Andalucía) y Sistema de Información Territorial de la Región de Murcia

\footnotetext{
${ }^{6}$ En concreto con la AIR Marina de Cope, planteaba una nueva "ciudad" de 60.000 habitantes en su máxima ocupación como reflejan VERA y ESPEJO (2006). Solamente esta actuación supone el doble de la población actual del término municipal de Águilas.
} 
FIGURA 4

Dinámicas poblacionales frente a ordenación del territorio

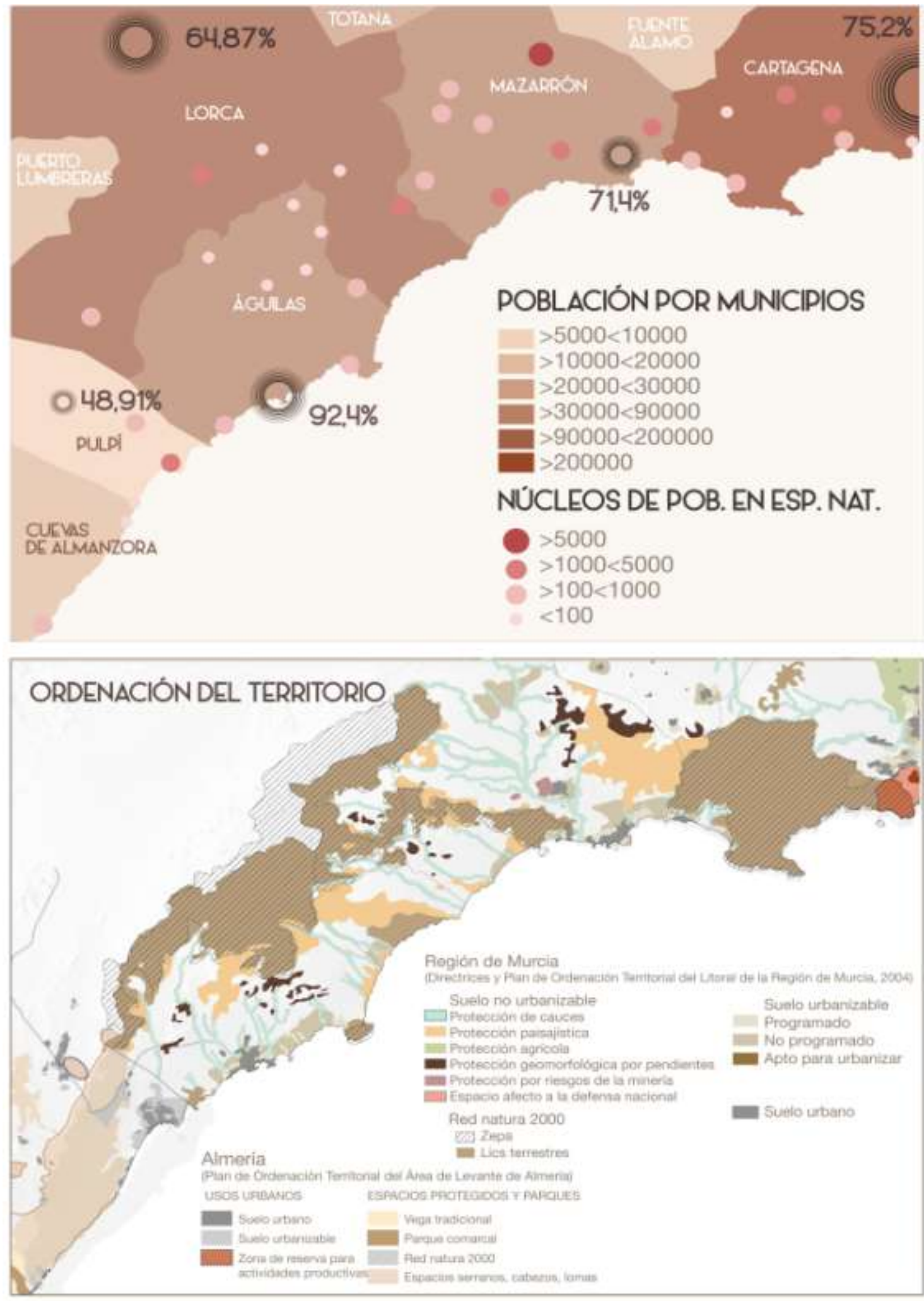

Fuente: Elaboración propia a partir de la información obtenida de Directrices y Plan de Ordenación del Litoral de la Región de Murcia, Consejería de Turismo y Deporte (Junta de Andalucía), Consejería de Desarrollo Económico, Turismo y Empleo (Región de Murcia), Centro Regional de Estadística de Murcia, Instituto de Estadística y Cartografía de Andalucía. 


\subsection{SIERRA DE LA ALMENARA}

La Sierra de la Almenara se desarrolla en sentido SO-NE y su divisoria constituye el límite entre los términos municipales de Lorca y Águilas, separando las laderas y pequeñas llanuras costeras de la zona de Águilas de la depresión interior del Guadalentín. Chuecos se encuentra en la zona noroeste de la sierra, en la comarca de Purias, entre el campo de Lorca al norte y el litoral de Águilas al sur, área que queda conectada en sentido N-S por la autovía Lorca-Águilas, y en E-O por la carretera nacional Águilas-Mazarrón, a escasos $2 \mathrm{~km}$ del paraje. La población de Tébar, desde la que se accede por el sur al valle, se encuentra en el punto de intersección entre ambas vías de comunicación. Estudiando los tiempos de desplazamiento en coche desde la finca a los principales núcleos de población de la sierra, así como la cercanía a equipamientos y puntos de singularidad e interés turístico de la misma, y la facilidad de conexión con itinerarios de senderismo homologados (PR y GR); se observa la buena ubicación de la finca para poder establecer buenas conexiones con el resto del territorio en posteriores fases de intervención (Figura 5).

FIGURA5

Ubicación de Chuecos en la Sierra de la Almenara y relación con la misma

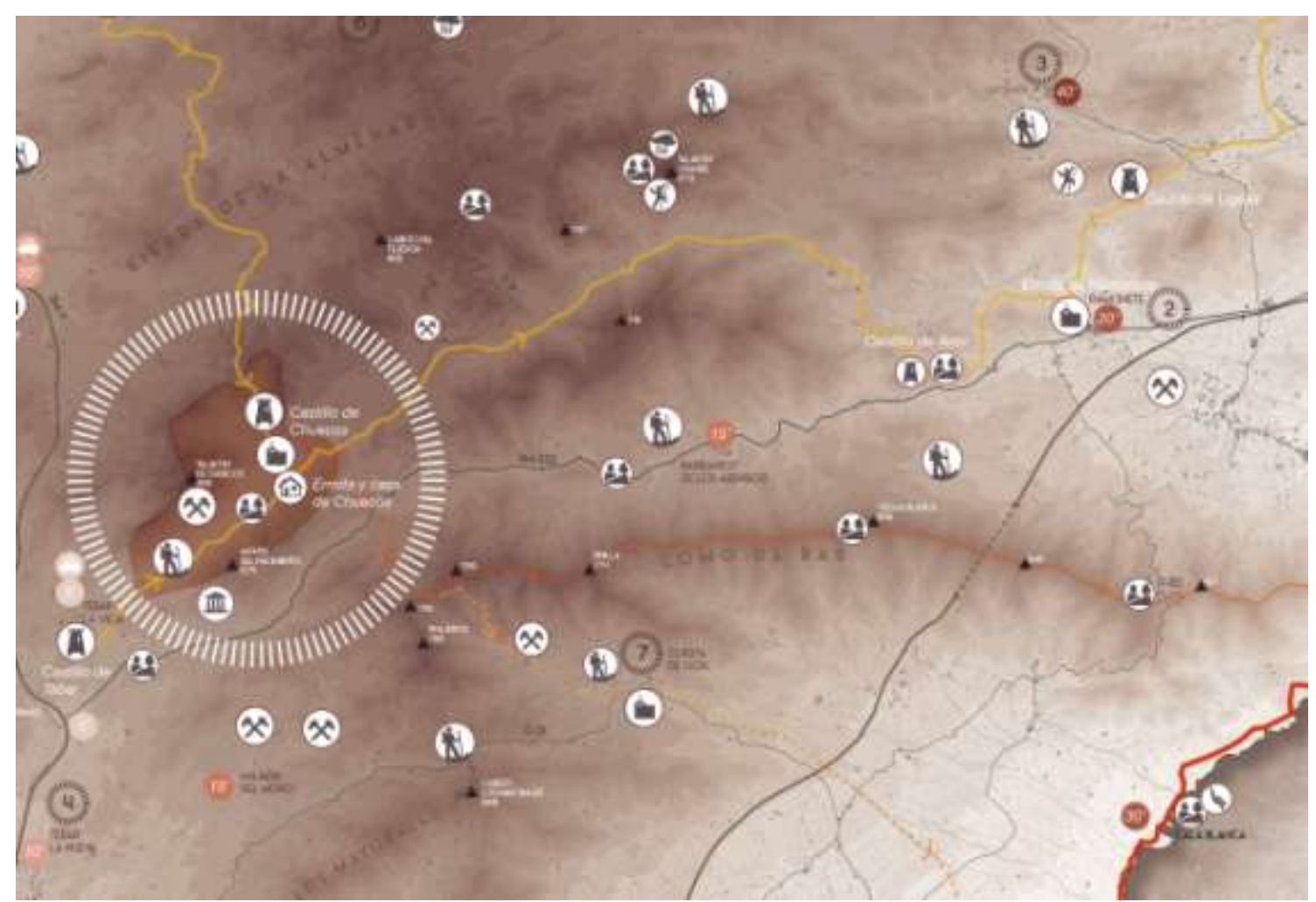

Fuente: Elaboración propia a partir de la cartografía del Instituto Geográfico Nacional

\subsection{PARAJE DE CHUECOS}

En el análisis paisajístico se llega a una división en 3 UP (en la que se tiene en cuenta solamente el interior de la cuenca del valle, ya que es el objeto de análisis) (Figura 6). UP1Camino de Chuecos, UP2-Valle de Chuecos, UP3-umbría del Talayón. La exposición visual de cada UP se evalúa según la visibilidad de las mismas desde 5 puntos considerados de visibilidad especial puesto que su cuenca visual abarca las tres UP (Figura 6). 
FIGURA 6

División en UP, identificación de ejes, hitos y puntos de máxima visibilidad

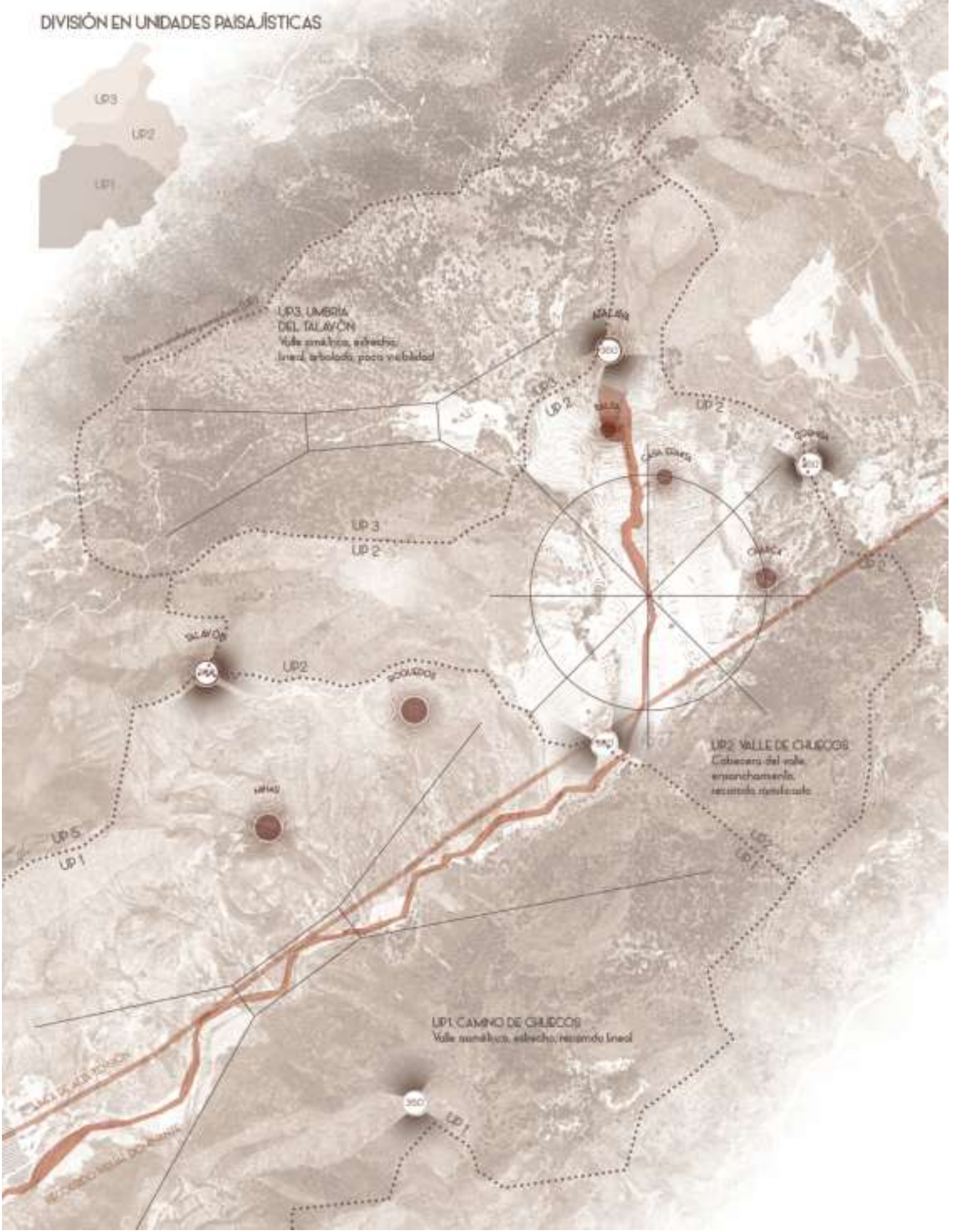

Fuente: Elaboración propia a partir de la cartografía del Instituto Geográfico Nacional

A continuación se evalúa el parámetro fragilidad visual, basado en tres otros factores (calidad, absorción, exposición). Este cuarto parámetro, unido al mapeado de cuencas visuales, permitirá, en fase de proyecto, llegar a realizar un catálogo de niveles de protección visual dentro de cada unidad paisajística considerada (Figura 7). La evaluación de cada parámetro se basa en los siguientes criterios: 
CALIDAD VISUAL Variedad cromática, variedad de texturas, fuerza visual por fuertes pendientes, contrastes, asimetrías, escalas, ejes, diversidad ecológica, valores patrimoniales, existencia de hitos de especial valor paisajístico, rarezas. Se evalúa del grado 1 al 5.

EXPOSICIÓN VISUAL Ponderación de las superficies con diferentes exposiciones existentes dentro de la UP. Estas exposiciones se calculan de manera cuantitativa mediante análisis de visibilidad desde los puntos del paraje que mayor cuenca visual ofrecen. Se divide en 5 grados de exposición (Figura 7).

CAPACIDAD DE ABSORCIÓN VISUAL La capacidad de absorción visual se evalúa de forma perceptiva, en cuanto a existencia de elementos en los que la visibilidad es baja y por tanto ofrecen mayor absorción (bosque cerrado de umbría, relieve accidentado, cerros, vaguadas, lechos de rambla).Se evalúa del grado 1 al 5 .

FRAGILIDAD VISUAL. Los tres parámetros anteriores se ponderan a fin de obtener un nivel de fragilidad visual para cada UP (Figura 8), lo que permitirá establecer niveles de protección, usos y actividades permitidos, etc.Nivel 1: poco frágil. Nivel 2: frágil. Nivel 3: muy frágil.

FIGURA 7

Obtención de niveles de exposición visual y parámetros de evaluación paisajística
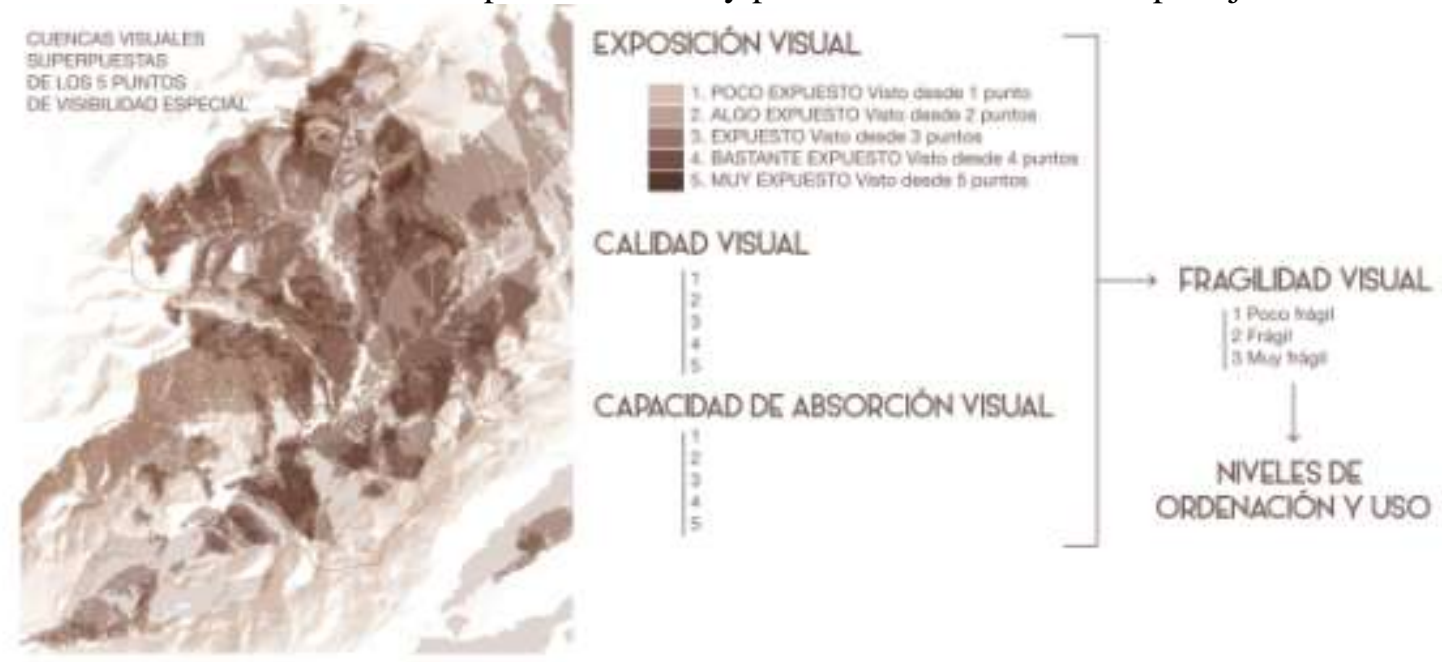

Fuente: Elaboración propia a partir de la cartografía del Instituto Geográfico Nacional

FIGURA 8

Valoración cualitativa de las UP y determinación del nivel de fragilidad visual
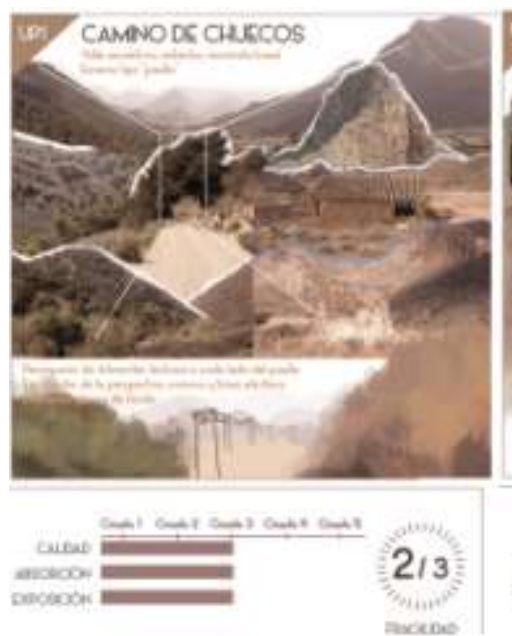
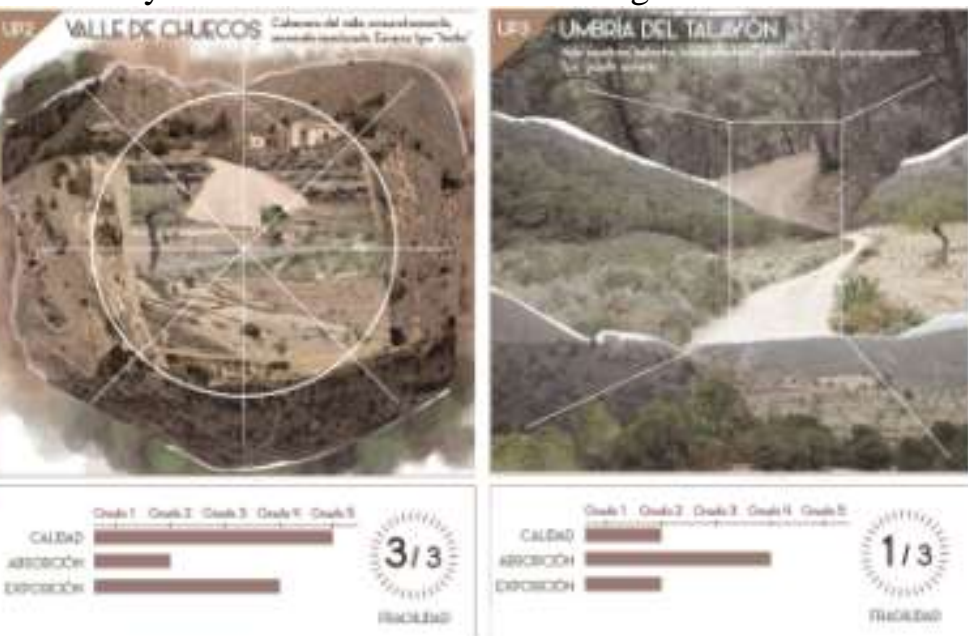

Fuente: Elaboración propia a partir de croquis y fotografías. 


\section{RESULTADOS Y DISCUSIÓN. FASE GENERACIÓNDE LA PROPUESTA}

\subsection{DESCOMPOSICIÓN DE "ESTRUCTURAS”}

La primera capa de observación en la que se basa la generación de la propuesta de gestión del paisaje es la de las "estructuras", que consisten en las unidades de descomposición en las que se divide el lugar para su análisis.

En el lugar encontramos diferencias, a veces claras y tajantes y otras veces sutiles y disimuladas, entre dos conceptos estructurales clave: las zonas del lugar que en la actualidad tienen un estado "natural" o "salvaje" casi inalterado, y las zonas del lugar que tienen un carácter "humanizado", en las que el nivel de antropización varía desde la existencia de una pequeñísima zona de cultivo hasta la excavación de una mina, o la construcción de un conjunto arquitectónico. La diferenciación entre estas zonas comienza a delimitar una ordenación (Figura 9).

Dentro de esta primera diferenciación estructural, se llega a obtener las "unidades mínimas" que sostienen la conformación del lugar: el "ecosistema" y la "terraza".

ECOSISTEMA: Porción de territorio caracterizado por un tipo de hábitat o cultivo (según grado de uso agrícola). Generado por dos agentes: la propia conformación natural del lugar (las pendientes, la insolación y la orientación, el suelo, el agua, la exposición al viento) y la distribución de la explotación agrícola por parte del hombre (las zonas en las que se cultiva cereal, las de regadío, las de almendro y olivo de secano, etc.), también condicionada lógicamente por la naturaleza. Estos diferentes ecosistemas en la realidad no tienen unos límites perfectamente acotados sino que conforman una composición dirigida por la mezcla, la superposición, las sinergias y la diversidad; reglas internas que serán clave en el proyecto.

TERRAZA: Porción de terreno explanado por acción humana en contra de la pendiente, a fin de producir un suelo con condiciones aptas para el cultivo. El aterrazado del terreno es una actuación puramente antrópica, que da respuesta a los condicionantes de la naturaleza buscando un máximo aprovechamiento de los recursos (escorrentía, orientación, insolación, exposición al viento, calidad del suelo...) ofrecidos por esta: su forma y función se adapta perfectamente a las características del lugar concreto en el que se inserta. Esta unidad estructural ha supuesto durante siglos un símbolo del nivel de adaptación y comprensión del territorio por parte del ser humano; ha sido básica en la práctica de la agricultura de subsistencia y representa un patrimonio cultural que merece la pena valorar.

Estas unidades mínimas se relacionan generando estructuras mayores. Los "ecosistemas", por una parte, funcionan como teselas que conforman un "MOSAICO" (Figura 9), en el que cada pieza revela información sobre las características del lugar en ese punto (un ecosistema de vegetación de rambla indica naturalidad, fuertes pendientes, presencia de agua... Mientras que uno de almendro de secano indica antropización, pendiente suave y escasez hídrica). Por otro lado, las diferentes relaciones formales y agrupaciones que existen entre las terrazas (tamaño, proporción, orientación, concentración de unidades por hectárea) también generan un sistema superior, un "ATERRAZADO" (Figura 9) que contiene a su vez información sobre el territorio (un número elevado de unidades por hectárea y de pequeño tamaño suele estar relacionado con un uso de regadío, una orientación determinada con un tipo determinado de cultivo, etc.)

Resumiendo estos tejidos y las relaciones entre los mismos, se puede decir que el "mosaico" hace referencia a las características del territorio a través de una red de puntos ("teselas"), mientras que el "aterrazado" expresa el grado de aprovechamiento que el ser humano ha obtenido a partir de ese "mosaico".

El proyecto desarrollado busca instalarse dentro de este "mosaico aterrazado", siguiendo sus mismas directrices: el aprovechamiento máximo de los recursos del lugar gracias al entendimiento del mismo y con la utilización de la diversidad, la sinergia y la mezcla como reglas internas de desarrollo. 


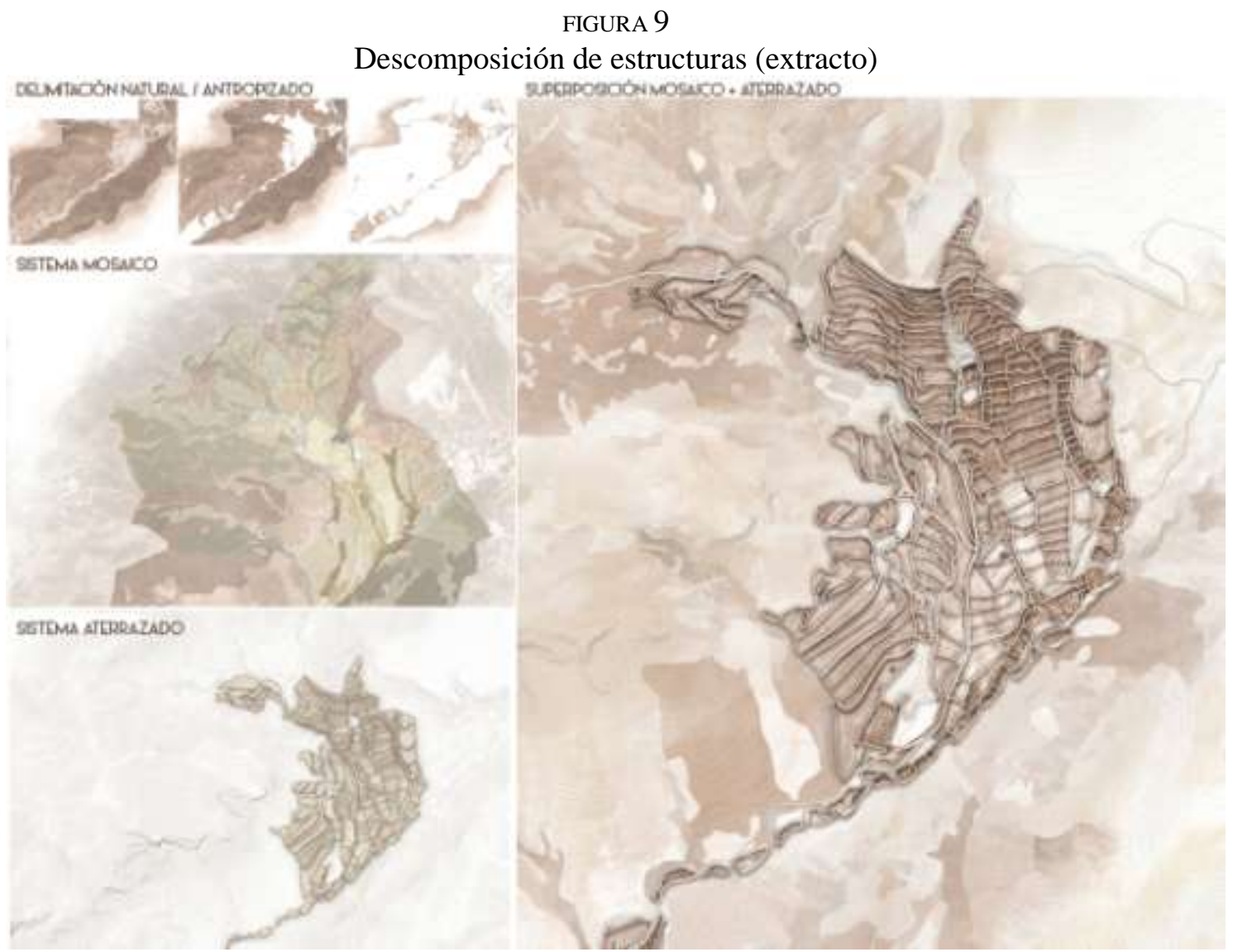

Fuente: Elaboración propia a partir de la cartografía del Instituto Geográfico Nacional

\subsection{DESCOMPOSICIÓN DE “ACTIVIDADES” Y “TEMAS”}

Las actividades que se plantean en Chuecos responden a motivos ya expuestos (experimentar con modelos alternativos de desarrollo y gestión rural, paisaje como recurso). Actualmente los usos desarrollados en la finca, promovidos por los propietarios, se agrupan en: producción agrícola, educación, investigación, turismo.

Se propone potenciar las actividades existentes, mediante estos cuatro usos (cada uno centrado en un tipo de actividad, pero superpuesto a otras complementarias) (Figura 10). Esta superposición da lugar a un programa que se ve materializado en diferentes actuaciones, incluyendo la creación de objetos arquitectónicos denominados "cabañas". Este programa es abierto y variable, y depende de la demanda y de la situación económica en la que se encuentre el parque. Por lo tanto, la configuración de las piezas arquitectónicas-cabañas debe ser adaptable a los diferentes escenarios, lo que implicará características de modulación, prefabricación, facilidad de montaje y desmontaje, mínima intervención en el terreno, etc.

En un proyecto en el que se pretende comunicar, divulgar el conocimiento sobre un lugar, se considera imprescindible entender "de qué trata" ese lugar, cuáles son sus "temas": esta es la tercera capa de descomposición del lugar en la que se desarrolla la generación proyectual (estructura, actividades y temas), y consiste en describir el "argumento" del mismo. 
FIGURA 10

Descomposición de actividades (extracto)

Programo de oclividades propuestos

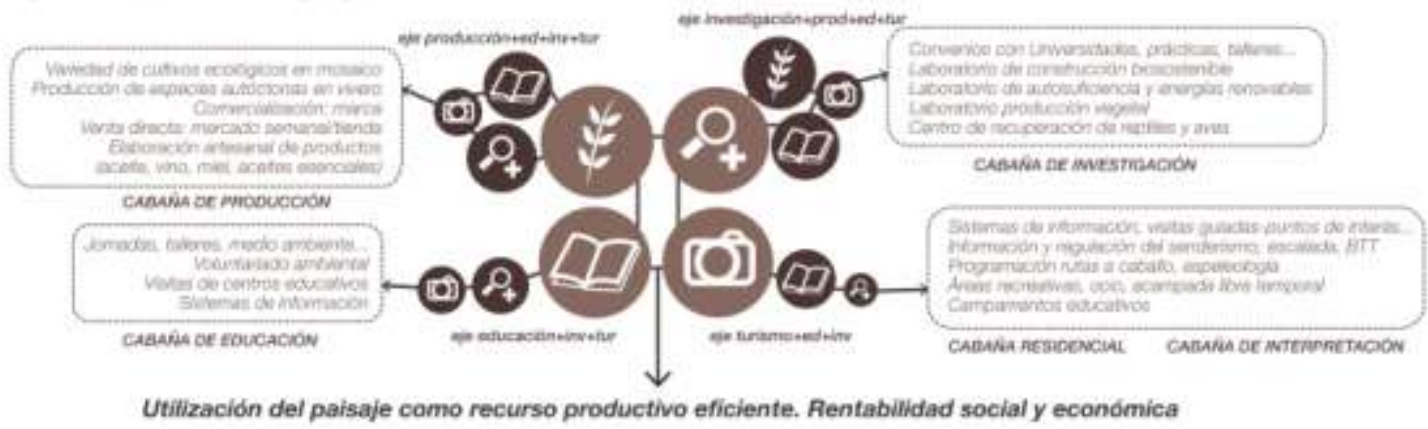

Fuente: Elaboración propia

FIGURA 11

Temas, áreas y grados de superposición temática y actividades permitidas según el grado

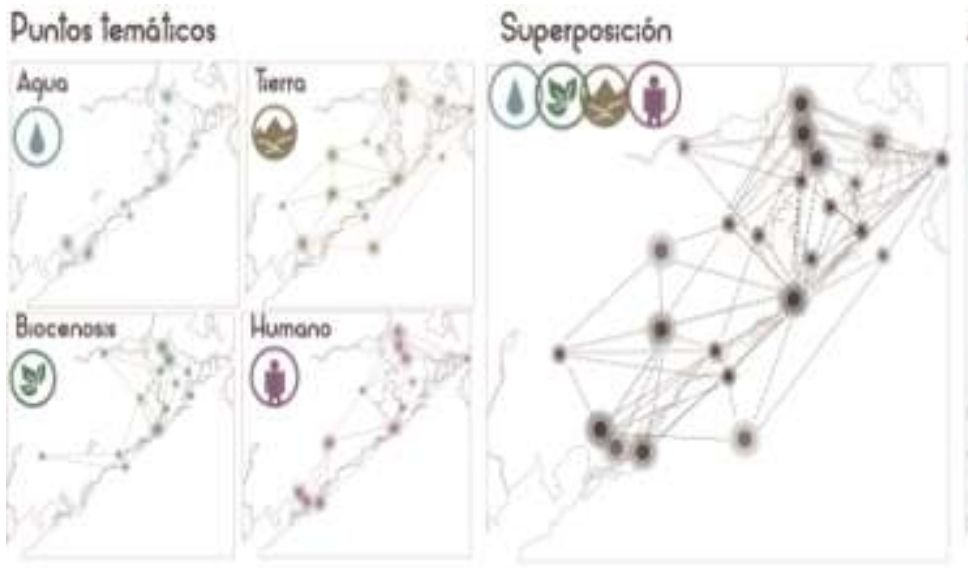

Áreos de superposición

Aclividades e infraesirucluros permilidas según grodo de superposición lemática

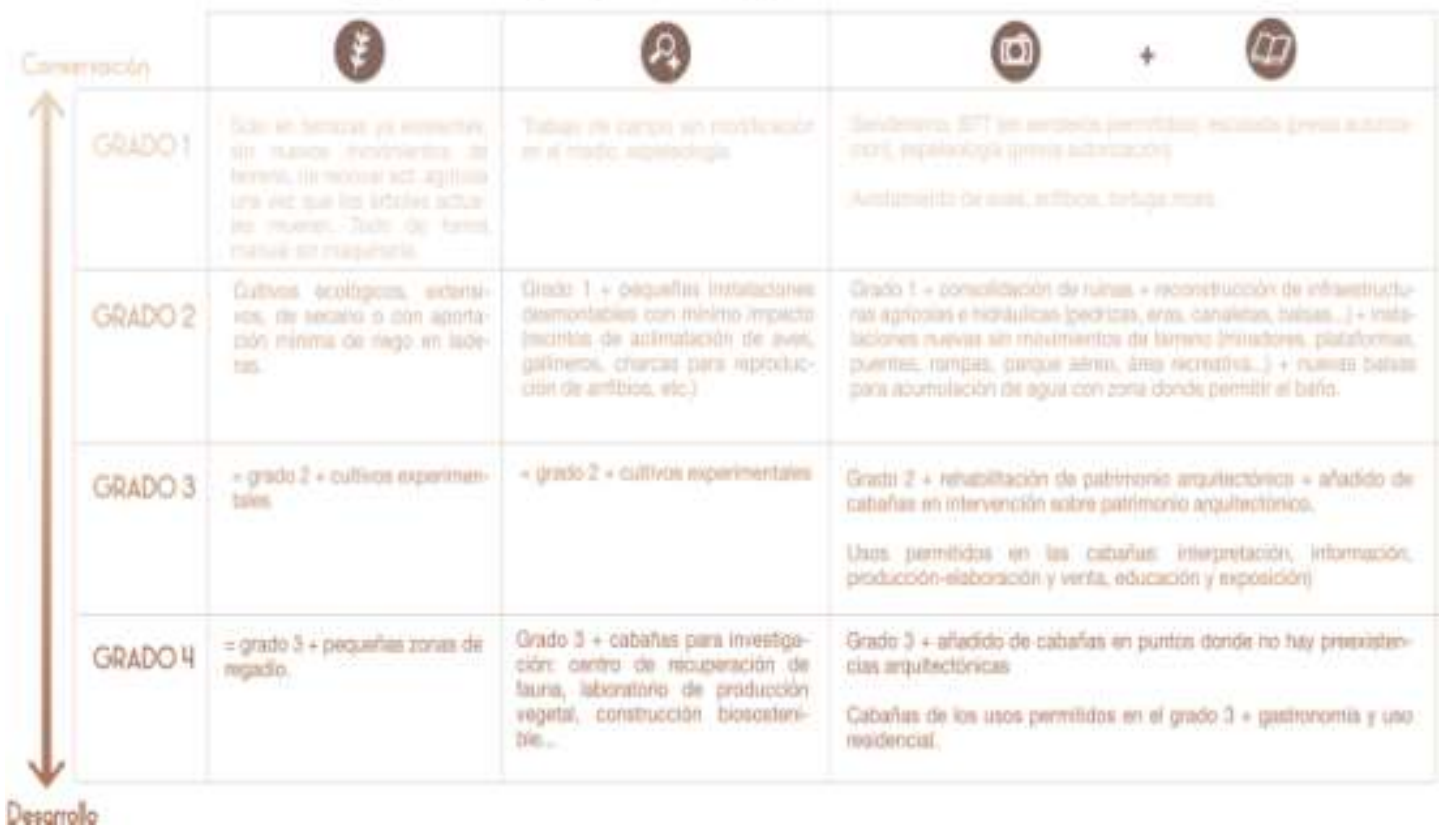

Fuente: Elaboración propia 
Se pretende comunicar la historia de un lugar representativo de los ecosistemas propios de una unidad territorial, de una cultura, un paisaje, unos recursos naturales y una historia de ocupación humana comunes a una extensión de territorio. Por lo tanto, esta narración se basa en una serie de temas que debemos extraer del lugar. El primero y más evidente es el agua: su existencia define el lugar donde se desarrolla un asentamiento, y por tanto donde ocurre la modificación humana del paisaje, y desarrolla los recorridos en el mismo. Junto al agua aparece la tierra, la topografía, geomorfología, el biotopo, agente conformador del paisaje y condicionante de la forma de ocupación humana. Y en unión con este, la biocenosis, los seres que habitan en estos espacios y que tienen unas características concretas que derivan de los dos temas anteriores. Y por último, aparece el ser que ha hecho uso de estos espacios, que ha sido condicionado por todos los temas anteriores: el ser humano.

Estos cuatro temas (el agua, la tierra, la biocenosis, el ser humano) son los elementos cuya lectura a lo largo de la historia permite el entendimiento del lugar, por lo que el objetivo del proyecto es hacerlos visibles, entendibles, valorizarlos y conectarlos. Es aquí donde nace el concepto de "Parque Ecotemático del Levante Semiárido": lugar donde se ponen en valor, desde una perspectiva ecológica y sostenible, los temas que permiten el conocimiento del territorio.

De la observación y análisis de la estructura física y paisajística del lugar se llega a obtener los puntos especialmente representativos de un tema (o varios). De este estudio se extrae un total de 24 "puntos temáticos" que generan cuatro diagramas diferentes, referentes a cada tema, con sus correspondientes recorridos. Por último, el diagrama de superposición entre estas variables revela cuáles son las zonas de mayor intensidad de interés (Figura 11).

Esta división en "áreas" según grado de superposición temática permite establecer criterios de ordenación y uso para cada una de ellas, generando una gradación de niveles de intervención. De esta forma, quedan asignados diferentes criterios de inserción de actividades a cada área del parque, en los que se basarán las intervenciones realizadas (Figura 11).

\section{RESULTADOS Y DISCUSIÓN. PROYECTO EXPERIMENTAL DE INTERVENCIÓN}

A partir del análisis realizado se llega a la identificación de tres zonas ("FOCOS") en las que existe una mayor concentración de rasgos característicos del lugar.

Estos "focos" se encuentran unidos por un itinerario, ya existente, que parte del acceso principal (al suroeste del valle, desde la aldea de Tébar) y asciende por el fondo del valle hasta llegar a la cabecera del mismo. Se pretende reforzar este "recorrido dominante" usándolo como hilo argumental para describir el lugar, pasando a través de los focos como partes de la historia que van permitiendo al visitante el descubrimiento y entendimiento de sus características; finalizando en la parte superior del valle, donde se encuentra el motivo de la existencia del mismo: el nacimiento de agua. Es también una forma de concienciar sobre la importancia del agua en los territorios semiáridos.

Por tanto los focos forman parte de la historia que se pretende relatar. Empezando en INICIO, se introduce al visitante en el parque, dándole la bienvenida, y exponiendo los temas de la narración. En esta parte existe un hilo a seguir claro, lineal, con pocas variantes, que continúa hasta DESARROLLO. Aquí la historia se expande, permitiendo diferentes líneas que nos dan a conocer diferentes aspectos del lugar, y que acabarán llevando al mismo punto en DESENLACE, donde el relato se va cerrando hasta llegar a su fin.

El Plan de Actuación de Chuecos pretende que esta lectura que se realiza del lugar sea lo más intuitiva posible y llegue al visitante de la manera más natural y sutil, siendo el propio lugar el que va desvelando las claves para su entendimiento. Por ello los criterios de actuación se basan en realizar intervenciones mínimas y concretas. La intención es que esta versión de lectura y entendimiento del lugar sea tan válida como las que el ser humano pasado y futuro ha realizado y realizará sobre el mismo, que se instale en la línea de tiempo de existencia del lugar como una etapa más, de manera reversible y fácilmente eliminable en un posible escenario futuro en el que esta interpretación ya no tenga sentido.

Para ello se plantean actuaciones en tres líneas: Actuaciones en comunicaciones y accesos, Actuaciones agrícolas-hidráulicas-paisajísticas, y Actuaciones arquitectónicas-paisajísticas; 
desarrolladas en profundidad en el mencionado Proyecto Final de Grado. Esta serie de actuaciones podrían ser exportables a lugares y experiencias similares en la zona de la Sierra de la Almenara y el área semiárida en general (Figura 12).

FIGURA 12

Plan de Actuación (extracto)

\section{PLAN DE ACTUACIÓN}

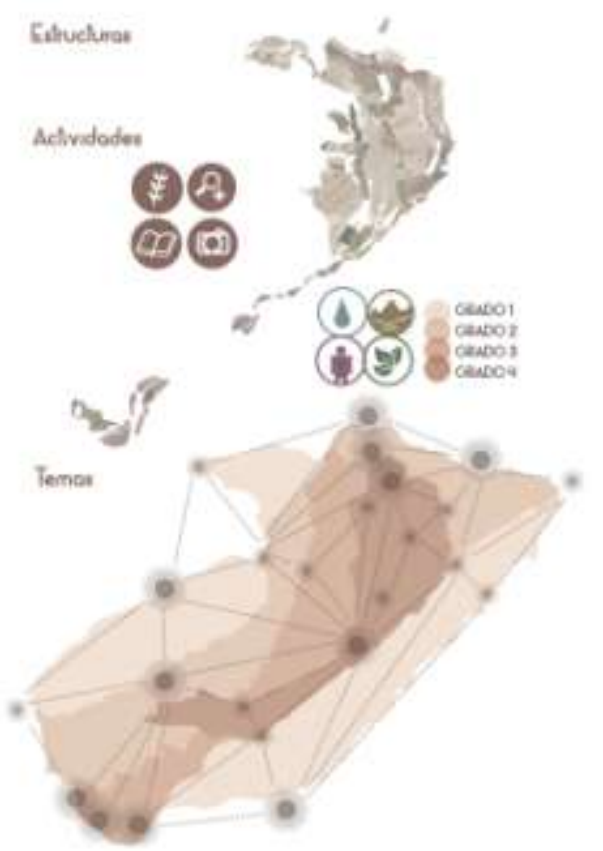

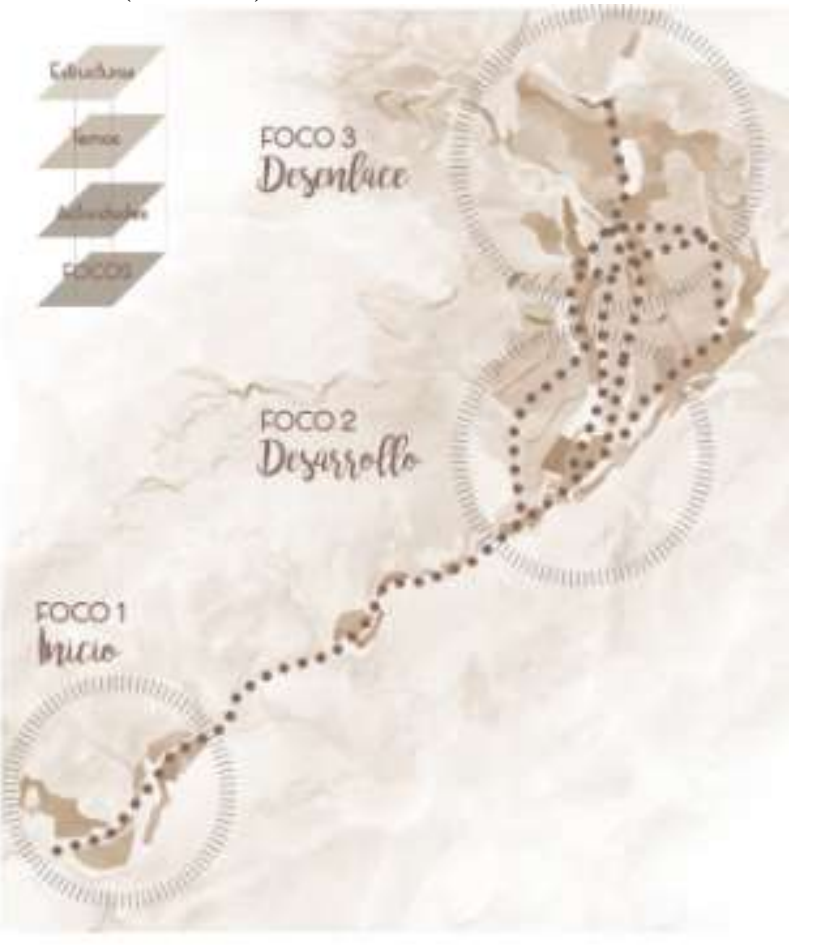

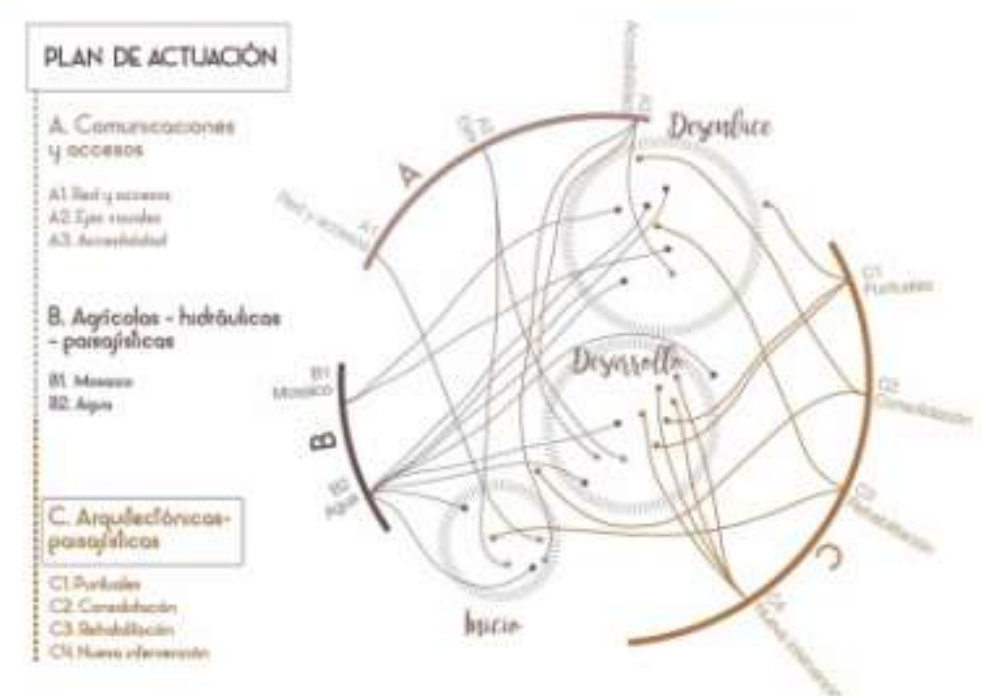

Fuente: Elaboración propia

\section{CONCLUSIONES}

El análisis multiescalar lleva a concluir que el paisaje semiárido tiene una gran calidad visual $\mathrm{y}$ unas características propias que lo hacen válido para proponer modelos de desarrollo y turismo alternativos, que ayuden a comprenderlo y valorarlo. Los espacios naturales del litoral suroeste de la Región ofrecen una gran potencialidad. Para esto es necesario promover iniciativas relacionadas con la educación y la divulgación, así como la participación ciudadana 
en materia de conservación y apreciación del paisaje, custodia del territorio, etc. A fin de desarrollar una percepción positiva del mismo en la sociedad.

A su vez es necesario respaldar la agricultura sostenible, ecológica y respetuosa con el entorno, ya que esta ha sido históricamente el principal agente moldeador del paisaje rural. En muchos casos, la existencia de un paisaje concreto está ligada a una actividad agrícola concreta por lo que es necesario asegurar su continuidad mediante subvenciones y otras herramientas para poder hablar de conservación del paisaje.

Otra conclusión derivada del análisis es que las figuras de ordenación territorial hasta la fecha no han contemplado el paisaje como recurso, por lo que se considera necesario realizar más estudios y análisis sobre el mismo para establecer nuevas directrices de ordenación que incluyan este factor. Para esto se considera importante una mayor comunicación entre los organismos públicos encargados de la ordenación territorial y el colectivo académicoprofesional a fin de establecer métodos de investigación sobre estos territorios que concluyan en un entendimiento profundo y exhaustivo de sus reglas internas para proponer actuaciones razonadas y acordes con las mismas.

Los resultados de investigaciones y propuestas experimentales como esta buscan despertar concienciación, colaboración y transmitir conocimiento, en un intento por motivar la creación de experiencias similares. La metodología seguida en la generación de la propuesta de gestión podría ser exportada a otros lugares.

\section{BIBLIOGRAFÍA}

AGUILÓ ALONSO, M. et al. (2004). Guía para la elaboración de estudios del medio físico. Contenido y metodología. Madrid, Ministerio de Medio Ambiente

ANDRÉS SARASA, J.L. (1995) Urbanismo contemporáneo: la Región de Murcia. Universidad de Murcia.

ANDRÉS SARASA, J.L. (2004) Incertidumbres en el espacio agrícola y proceso urbanizador "resort" en la Región de Murcia. En Cuadernos de Turismo, nº14, pp. 7-65. Murcia, Universidad de Murcia.

ANDRÉS SARASA, J.L. (2008) Evaluación del potencial turístico de los espacios rurales. En Turismo rural y desarrollo local,pp. 153-160. CEBRIÁN F. (coord.). Universidad de Sevilla, Universidad de Castilla-La Mancha.

ANDRÉS SARASA, J.L. (2014) El turismo en los procesos de desarrollo rural. En Papeles de Geografía, n59-60, pp. 17-36. Murcia, Universidad de Murcia

CEBRIÁN ABELLÁN, F. (2008) Turismo rural y desarrollo local: relaciones, desafíos, propuestas. En Turismo rural y desarrollo local, pp. 11-28. CEBRIÁN F. (coord.). Universidad de Sevilla, Universidad de Castilla-La Mancha.

CONESA GARCÍA, C., y ALONSO SARRIA, F. (2006) El clima de la Región de Murcia. En El medio físico de la Región de Murcia, CONESA C. et al. (eds.) Capítulo 3, pp.95-127. Murcia, Universidad de Murcia

ESCRIBANO M, M DE FRUTOS, E IGLESIAS, C MATAIX \& I TORRECILLA (1991) El Paisaje. Ministerio de Obras Públicas y Transportes, Secretaría General Técnica, Centro de Publicaciones, Madrid. 117 pp.

ESPARCIA PÉREZ, J., NOGUERA TUR, J., PITARCH GARRIDO, M.J. (coord.) (2009) Gestión y promoción del desarrollo local. Universidad de Valencia

ESPEJO MARÍN, C. (2008) El papel de los instrumentos de planificación en las dinámicas productivas y territoriales. En Turismo rural y desarrollo local. Pp. 161-170. CEBRIÁN F. (coord.). Universidad de Sevilla, Universidad de Castilla-La Mancha.

HILDENBRAND SCHEID, A. (2007) Tres propuestas para una relación efectiva entre las escalas regional y local en materia de ordenación del territorio. En Territorialidad y buen gobierno para el desarrollo sostenible. Nuevos principios y nuevas politicas en el espacio europeo. Pp. 147-190.FARINÓS, J.et al. (eds.) Universidad de Valencia

IBARRA MARINAS, D., BELMONTE SERRATO, F., RUBIO IBORRA, J. (2017) El impacto territorial del uso agrícola y turístico del litoral: evolución de los cambios de uso del suelo en 
las cuencas litorales del sur de la Región de Murcia (1956-2013). En Boletín de La Asociación de Geógrafos Españoles, (73), pp. 295-312.

LÓPEZ BERMÚDEZ, F., ALONSO SARRIA, F., CONESA GARCÍA C. (2003) Los escenarios físicos de la Región de Murcia: diversidad y valor. En Los recursos naturales de la Región de Murcia. Un análisis interdisciplinar, ESTEVE M.A. et al. (eds.) Capítulo 1, p.15-3. Murcia, Universidad de Murcia.

LÓPEZ CUQUEJO, A. (2002) Agricultura, turismo y recursos hídricos en el Levante almeriense. En Papeles de Geografía, n⿳355, pp. 211-225. Murcia, Universidad de Murcia

MARTÍN GARCÍA, J. (2010) La explosión urbana del litoral. Transformación de los usos del suelo en los municipios de Garrucha, Mojácar y Vera. Universidad de Valencia

MARTÍNEZ FERNÁNDEZ J., y ESTEVE SELMA, M.A. (coord.) (2009) Sostenibilidad ambiental en la Región de Murcia. Universidad de Murcia

PÉREZ MORALES, A., GIL GUIRADO, S., GARCÍA MARTÍN, F. M. (2015). Veinte años de protección de cauces en el litoral de la Región de Murcia (1994-2014). Evaluación de la eficiencia de las medidas de Ordenación del Territorio. En Anales de Geografía de La Universidad Complutense, 35(1), pp. 169-185.

ROMERO DÍAZ, A. y BELMONTE SERRATO, F. (2002) Los paisajes geomorfológicos de la Región de Murcia como recurso turístico. En Cuadernos de Turismo, n9, pp. 103-122. Murcia, Universidad de Murcia

SANTOS PAVÓN, E., FERNÁNDEZ TABALES, A., MUÑOZ YULES, O. (2016) La incorporación del paisaje a la planificación turística. Análisis de la estrategia de turismo sostenible de Andalucía. En Cuadernos de Turismo, n³7, pp. 175-202. Murcia, Universidad de Murcia

VERA REBOLLO, F. y ESPEJO MARÍN, C. (2006) El papel de los instrumentos de planificación en las dinámicas productivas y territoriales: las Directrices y el Plan de Ordenación del Litoral de la Región de Murcia. En Gobernanza territorial en España. Claroscuros de un proceso a partir del estudio de casos. Capítulo III, pp. 61-79. ROMERO, J. et al.(eds.) Valencia, Universidad de Valencia

\section{Figuras de planeamiento, ordenación y gestión}

Directrices y Plan de Ordenación Territorial del Litoral de la Región de Murcia, aprobadas en junio de 2004.

Plan de Ordenación del Territorio del Levante Almeriense, aprobado en febrero de 2009.

Plan de Gestión y Conservación de la Zona de Especial Protección para las Aves (ZEPA) de Almenara, Moreras y Cabo Cope, aprobado en noviembre de 2010.

Plan de Gestión de la finca Castillo de Chuecos (2005). Elaborado por Fundación Castillo de Chuecos, FundacióTerritori i Paisatge, LYCSA. 